\title{
The out-of body experience: precipitating factors and neural correlates
}

\author{
Silvia Bünning and Olaf Blanke*
}

\begin{abstract}
Laboratory of Cognitive Neuroscience, Ecole Polytechnique Fédérale de Lausanne (EPFL), Lausanne, Switzerland and Department of Neurology, University Hospital, Geneva, Switzerland
\end{abstract}

\begin{abstract}
Out-of-body experiences (OBEs) are defined as experiences in which a person seems to be awake and sees his body and the world from a location outside his physical body. More precisely, they can be defined by the presence of the following three phenomenological characteristics: (i) disembodiment (location of the self outside one's body); (ii) the impression of seeing the world from an elevated and distanced visuo-spatial perspective (extracorporeal, but egocentric visuo-spatial perspective); and (iii) the impression of seeing one's own body (autoscopy) from this elevated perspective. OBEs have fascinated mankind from time immemorial and are abundant in folklore, mythology, and spiritual experiences of most ancient and modern societies. Here, we review some of the classical precipitating factors of OBEs such as sleep, drug abuse, and general anesthesia as well as their neurobiology and compare them with recent findings on neurological and neurocognitive mechanisms of OBEs. The reviewed data suggest that OBEs are due to functional disintegration of lower-level multisensory processing and abnormal higher-level self-processing at the temporo-parietal junction. We argue that the experimental investigation of the interactions between these multisensory and cognitive mechanisms in OBEs and related illusions in combination with neuroimaging and behavioral techniques might further our understanding of the central mechanisms of corporal awareness and self-consciousness much as previous research about the neural bases of complex body part illusions such as phantom limbs has done.
\end{abstract}

\section{Introduction}

In an out-of-body experience (OBE) people seem to be awake and feel that their "self," or center of experience, is located outside of the physical body. It is from an elevated extracorporeal location that the subjects who undergo an OBE experience seeing their body and the world. The following example from Irwin (1985; case 1) may illustrate what subjects experience during an OBE:

I was in bed and about to fall asleep when I had the distinct impression that

\footnotetext{
*Corresponding author. Tel.: +4121 6939621;

Fax: + 4121 6939625; E-mail: olaf.blanke@epfl.ch
}

\begin{abstract}
"I" was at the ceiling level looking down at my body in the bed. I was very startled and frightened; immediately [afterwards] I felt that, I was consciously back in the bed again.
\end{abstract}

An OBE is defined by the presence of three phenomenological characteristics: (i) disembodiment (location of the self outside one's body); (ii) the impression of seeing the world from an elevated and distanced visuo-spatial perspective (extracorporeal, but egocentric visuo-spatial perspective); and (iii) the impression of seeing one's own body (autoscopy) from this perspective (Green, 1968; Blackmore, 1982a; Blanke et al., 2004). This is illustrated in Fig. 1. OBEs challenge the 


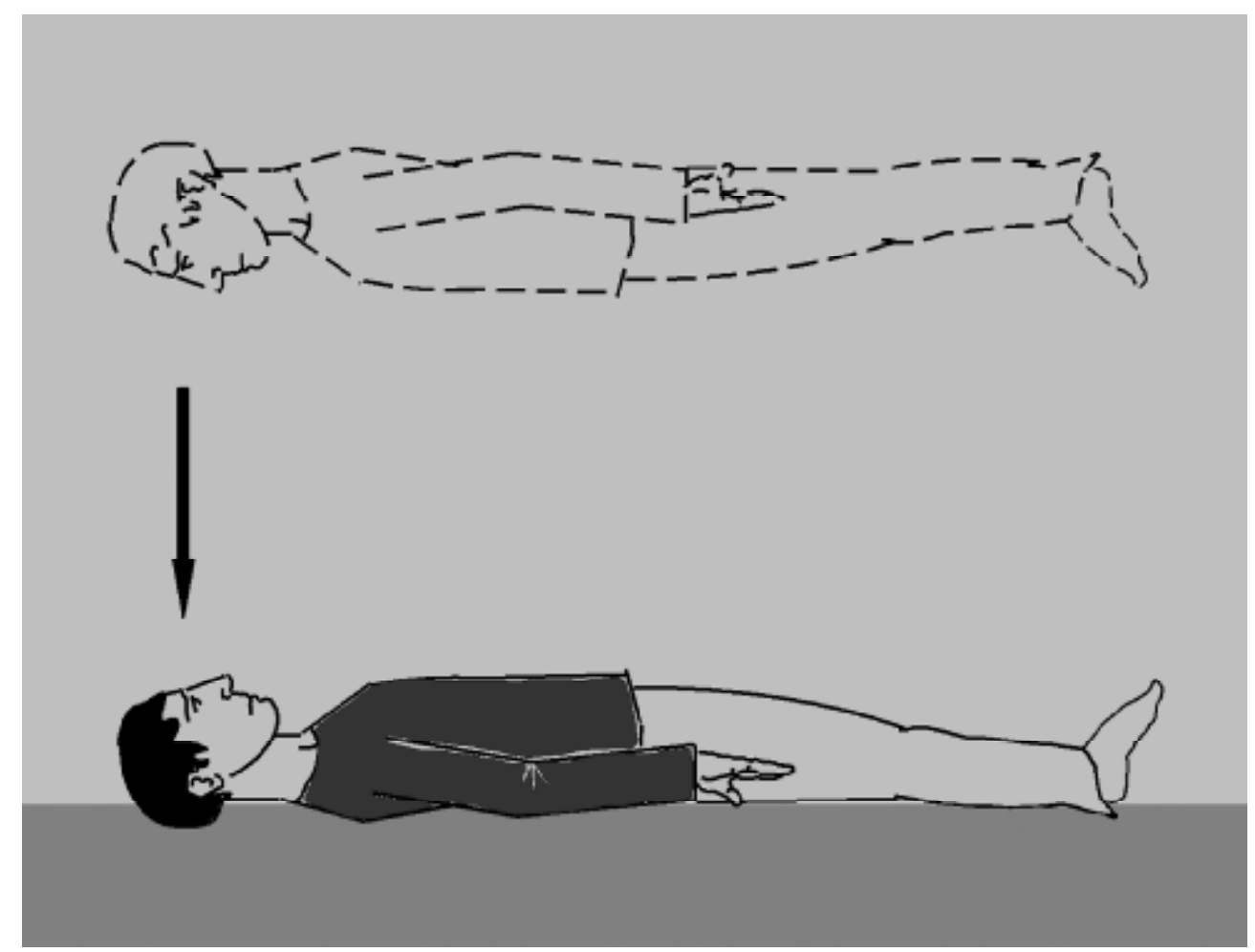

Fig. 1. Phenomenology of out-of-body experience (OBE). During an OBE the subject appears to "see" his/her body (bottom figure) and the world from a location above his physical body (extracorporeal location and visuo-spatial perspective; top figure). The self is localized outside one's physical body (disembodiment). The direction of the subject's visuo-spatial perspective during an OBE is indicated by an arrow (modified from Blanke, 2004).

experienced spatial unity of self and body or the experience of a "real me" that resides in one's body and is the subject of experience (Neisser, 1988; Gallagher, 2000; Metzinger, 2003, in press). This has also been suggested by psychologists (Palmer, 1978; Blackmore, 1982a; Irwin, 1985) and neurologists (Devinsky et al., 1989; Grüsser and Landis, 1991; Brugger et al., 1997; Blanke et al., 2004). These authors argued that OBEs are culturally invariant neuropsychological phenomena or deviant self models due to abnormal brain activation patterns whose scientific investigation might lead to a better understanding of the processes mediating the self under normal conditions.

Understanding how the brain generates the abnormal self during OBEs is particularly interesting since OBEs are not only found in clinical populations (Devinsky et al., 1989; Grüsser and Landis, 1991; Brugger et al., 1997; Blanke et al., 2004), but also appear in approximately $10 \%$ of the healthy population (Blackmore, 1982a; Irwin, 1985). Moreover, OBEs have been described in the majority of the world's cultures (Sheils, 1978). Yet, there are to date only few scientific investigations on OBEs, probably because they generally occur spontaneously, are of short duration, and happen only once or twice in a lifetime (Green, 1968; Blackmore, 1982a). This sparseness of scientific investigations is astonishing because other body illusions such as supernumerary phantom limbs or the transformation of an extremity (i.e., visual illusions of body parts) have been systematically investigated by many basic and clinical neuroscientists (see Ramachandran and Hirstein, 1998; Halligan, 2002, for review). Importantly, these latter studies have led to the description of neurophysiological and neuroanatomical mechanisms of visual body part illusions and to the development of more efficient treatments for the affected neurological patients. This is not the case for visual illusions of the entire body such as OBEs, which 
continue to occupy a neglected position between neuroscience and mysticism.

Several precipitating factors have been described for the OBE (Muldoon and Carrington, 1951; Crookall, 1964; Blackmore, 1982a; Irwin, 1985). Based on case collections, Muldoon and Carrington (1951) described in addition to spontaneously occurring OBEs, OBEs associated with illness, sleep, drugs, general anesthesia, accidents, and hypnosis. This was confirmed by the work of Crookall (1964) and several questionnaire studies (Blackmore, 1982a; Irwin, 1985). In the following, we will focus on several of these precipitating factors of OBEs and their brain correlates and review data in neurological and psychiatric disease, sleep and dreaming, marijuana use, general anesthesia as well as influences of body position and cognitive mechanisms.

\section{Neurology}

Only few neurological patients with OBEs due to brain damage have been reported in the last 50 years. Nevertheless, this has led to the description of etiology, associated phenomenology, and anatomy of OBEs (Devinsky et al., 1989; Brugger, 2002; Blanke et al., 2004; Blanke and Arzy, 2005). OBEs have been observed predominantly in patients with non-lesional and lesional epilepsy as well as migraine, and are generally classified with two other forms of autoscopic phenomena, autoscopic hallucination and heautoscopy. The three forms of autoscopic phenomena differ with respect to the three phenomenological characteristics of OBEs as defined above (disembodiment, visuospatial perspective, autoscopy). Whereas there is no disembodiment in autoscopic hallucinations and always disembodiment in OBEs, subjects with heautoscopy generally do not report clear disembodiment, but are not able to localize their self easily. Thus, in some cases the self may be localized at multiple positions including an extracorporeal position. Accordingly, the visuo-spatial perspective is body-centered in autoscopic hallucinations, extracorporeal in the OBE, and at different extracorporeal and corporeal positions in heautoscopy. The impression of seeing one's own body (autoscopy) is present in all three forms of autoscopic phenomena (for further details see Brugger et al., 1997; Blanke et al., 2004; Blanke and Arzy, 2005). Thus, during autoscopic hallucinations and heautoscopy the subject experiences seeing a double in extracorporeal space without disembodiment. Whereas during autoscopic hallucinations the double is generally experienced as an image and as an hallucination, during heautoscopy the double is often experienced as a three-dimensional person. In some heautoscopy cases the subject cannot even decide whether he or she is localized within the double (autoscopic body) or in the physical body (for further details see Blanke et al., 2004). In addition, subjects with heautoscopy often report to see in an alternating or simultaneous fashion from different visuo-spatial perspectives (physical body, double's body) as reported by patient 2B in Blanke et al. (2004).

Neurological authors have observed disturbed own body processing in patients with OBEs. Whereas Devinsky et al. (1989) observed the frequent association of vestibular sensations and OBEs, Grüsser and Landis (1991) proposed that a paroxysmal vestibular dysfunction might be an important mechanism for the generation of OBEs. In Blanke et al.'s (2004) study, the importance of vestibular mechanisms in OBEs was underlined by their presence in all patients with OBEs and by the fact that vestibular sensations were evoked by electrical stimulation in a patient at the same cortical site where higher currents induced an OBE (Blanke et al., 2002). In addition to vestibular disturbances, it has been reported that OBE-patients may also experience paroxysmal visual body-part illusions such as phantom limbs, supernumerary phantom limbs, and illusory limb transformations either during the OBE or during other periods related to epilepsy or migraine (Hécaen and Ajuriaguerra, 1952; Lunn, 1970; Devinsky et al., 1989; Blanke et al., 2002, 2004). Blanke et al. (2002) reported a patient in whom OBEs and visual body-part illusions were induced by electrical stimulation at the right temporo-parietal junction (TPJ). In this patient an OBE was induced repetitively by electrical stimulation whenever the patient looked straight ahead (without fixation of any specific object). If she fixated her arms or legs 
that were stretched out, she had the impression that the inspected body part was transformed leading to the illusory, but very realistic, visual perception of limb shortening (only the left arm, but both legs). If she fixated her arms or legs that were bent at the elbow or the knees she reported an illusory limb movement (only the left arm, but both legs) toward her face. Finally, with closed eyes the patient did not have either an OBE or a visual body-part illusion, but perceived her upper body as moving toward her legs (Blanke et al., 2002). These data suggest that visual illusions of body parts and visual illusions of the entire body such as autoscopic phenomena might depend on similar functional and anatomical mechanisms as argued by previous authors (Hécaen and Ajuriaguerra, 1952; Brugger et al., 1997).

Daly (1958), Lunn (1970), Devinsky et al. (1989), Blanke et al. (2004), and Maillard et al. (2004) have described OBE patients with circumscribed brain damage. These rare neurological cases allow to investigate whether certain brain areas or a hemisphere are linked to OBEs. In this patient sample, OBEs were due to epileptic seizures in the large majority of cases $(82 \%)$. Brain damage was due to neoplasia, posttraumatic brain injury, arteriovenous malformation, or a dysembryoblastic neuroepithelial tumor (accounting for $56 \%$ of the cases). Recently, Blanke et al. (2004; cases 1, 2a, and 3) performed lesion analysis based on magnetic resonance imaging (MRI) and showed involvement of the TPJ in all three of their OBE patients (Fig. 2). This was also found in the OBE-patient by Maillard et al. (2004; case 1). Moreover, Blanke et al. (2002) have shown that OBEs can be induced by electrical stimulation of the TPJ pointing to the importance of this region in the generation of OBEs. A recent review of all previously reported OBE-cases of focal neurological origin found that OBEs were related in $80 \%$ to right hemispheric brain damage (Blanke and Arzy, 2005). A lesion overlap analysis of all reported OBE-patients with focal brain damage or focal electroencephalographic (EEG) abnormalities is illustrated in Fig. 2.

Based on these neurological findings, Blanke et al. (2004) have recently proposed a model of OBEs that extended models by previous authors
(Blackmore, 1982a; Irwin, 1985; Grüsser and Landis, 1991; Brugger, 2002) and is also compatible with theoretical accounts for the affected body part in supernumerary phantom limbs (Ramachandran and Hirstein, 1998). Blanke et al. (2004) suggested that during an OBE the integration of proprioceptive, tactile, and visual information of one's body fails due to discrepant central representations by the different sensory systems. This may lead to the experience of seeing one's body (autoscopy) in a position (i.e., on a bed) that does not coincide with the felt position of one's body (i.e., under the ceiling; see above quoted example from Irwin, 1985). As OBEs are also characterized by disembodiment and elevated visuo-spatial perspective, Blanke et al. (2004) speculated that an additional vestibular dysfunction is present in OBEs. They suggested that OBEs are related to an integration failure of proprioceptive, tactile, and visual information with respect to one's own body (disintegration in personal space) and to a vestibular dysfunction leading to an additional disintegration between corporeal (vestibular) space and extracorporeal (visual) space. Both disintegrations were proposed to be necessary for the occurrence of an OBE. The neurological data also suggest that OBEs are due to a paroxysmal cerebral dysfunction of the TPJ in a state of partially impaired consciousness or awareness due to epilepsy or migraine.

\section{Psychiatry}

OBEs, autoscopic hallucinations and heautoscopy have been reported in psychiatric patients suffering from schizophrenia, depression, and personality disorders (Menninger-Lerchenthal, 1935; Lhermitte, 1939; Hécaen and Ajuriaguerra, 1952; Devinsky et al., 1989; Brugger et al., 1997; Blanke et al., 2004). Interestingly, we were only able to find two single case descriptions of psychiatric patients with OBEs, while the large majority experienced autoscopic hallucinations or heautoscopy. The 20 psychiatric patients that we analyzed suffered mainly from schizophrenia or depression and are listed in Table 1 . We could thus only find one diagnosed psychiatric OBE-case due to severe 


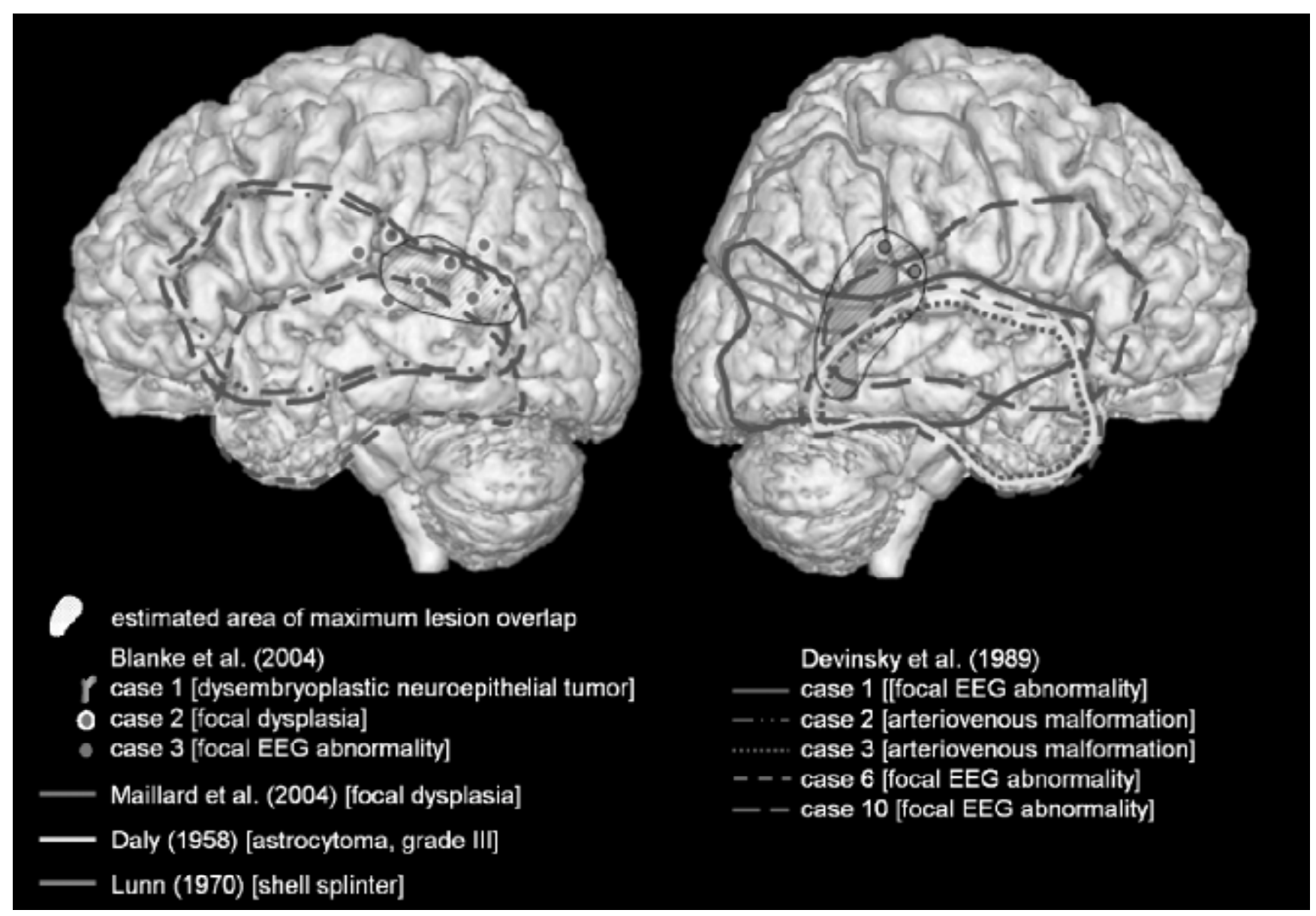

Fig. 2. Lesion location in OBE patients. MRI-based lesion overlap analysis of all previously reported OBE patients due to focal brain damage. The data for all patients are drawn on the MRI of one of the patients from Blanke et al. (2004). Lesion data are plotted separately for the left (left figure) and right hemisphere (right figure). For each study a different color was chosen: Daly (1958; yellow; 1 patient), Lunn (1970; green; 1 patient), Devinsky et al. (1989; blue; 5 patients), Blanke et al. (2004; pink; 3 patients), and Maillard et al. (2004; red; 1 patient). For the three patients by Blanke et al. (2004) the pink dots surrounded by white represent the zone of seizure onset for case 2, the pink dots surrounded by black represent the zone of seizure onset for case 3 , and the pink, shaded, area represents the area of lesion overlap for case 1 . Lesion location is indicated by cortical area surrounded by a line for each patient. The lesion sites of all patients by Blanke et al. (2004) were transformed to Talaraich space and transformed to the coordinates of the MRI of one of the patients. Thus, when the lesion location (or the epileptic focus) was described as right temporal, we marked the whole temporal lobe for that patient, if the lesion was characterized as left fronto-temporal parts of the fronto-temporal lobe were marked. The two patients with bilateral EEG abnormalities from Devinsky et al. (1989; cases 6 and 10) have been plotted on the right and left hemisphere. The regions of maximal overlap are indicated by the hatched area for each hemisphere and were found on the right and left TPJ. Most of the OBEs were due to interference with the right TPJ. See Blanke et al. (2004) for further details. See Plate 24.2 in Colour Plate Section.

depression (Hécaen and Green, 1957). In another psychiatric patient a full-blown OBE was reported (Zutt, 1953), but no psychiatric diagnosis was given. Thus, it seems that almost all of the previously reported psychiatric patients with autoscopic phenomena suffered from autoscopic hallucinations or heautoscopy. This is somewhat astonishing since it could be expected from the above-mentioned neurological findings that OBEs also exist more frequently in psychiatric patients, especially since OBEs are related functionally and anatomically to autoscopic hallucinations and heautoscopy (see above). Other authors have investigated OBEs in psychiatric patients, but did not report much phenomenological detail with respect to the OBEs of their patients other than stating that the phenomenology of a typical OBE in schizophrenic patients did not differ from the phenomenology of 
Table 1. Case reports of autoscopic phenomena of psychiatric origin. Twenty patients with autoscopic phenomenon due to psychiatric illness are listed. Only patients with sufficient phenomenological detail in order to classify the autoscopic phenomenon with respect to autoscopic hallucination (AH), heautoscopy (HAS), and OBE were included. Only two cases of OBE were found. AH and HAS were equally distributed

\begin{tabular}{|c|c|c|c|c|c|c|}
\hline \multirow[b]{2}{*}{ Case (Year) } & \multicolumn{3}{|c|}{ Psychiatric disorder } & \multicolumn{3}{|c|}{ Autoscopic phenomena } \\
\hline & Depression & Schizophrenia & Other & $\mathrm{AH}$ & HAS & $\mathrm{OBE}$ \\
\hline Aizenberg and Modai (1985) & $\mathrm{x}$ & & & $\mathrm{x}$ & & \\
\hline Alonso-Fernandez (reported in Damas Mora et al. (1972)) & & $\mathrm{x}$ & & & $\mathbf{x}$ & \\
\hline Arenz (2001) & $\mathrm{x}$ & & & & $\mathrm{x}$ & \\
\hline Craske and Sacks (1969) & $\mathrm{x}$ & & & & $\mathrm{x}$ & \\
\hline Damas Mora et al. (1980) & & $\mathrm{x}$ & & $\mathrm{x}$ & & \\
\hline Dening and Berrios (1994) (case 3) & $\mathrm{x}$ & & & $\mathrm{x}$ & & \\
\hline Hécaen and Green (1957) (case 3) & $\mathrm{x}$ & & & & & $\mathrm{x}$ \\
\hline \multirow[t]{2}{*}{ Letailleur et al. (1958) } & & $\mathrm{x}$ & & $\mathbf{x}$ & $\mathrm{x}$ & \\
\hline & $\hat{x}$ & & & $\mathrm{x}$ & & \\
\hline \multirow{2}{*}{ Lukianowicz (1958) (cases A, C, D, G) } & & $\mathrm{x}$ & & $\mathbf{x}$ & & \\
\hline & & $\mathrm{x}$ & & $\mathrm{x}$ & & \\
\hline Maack and Mullen (1983) & & $\mathrm{x}$ & & $\mathrm{x}$ & & \\
\hline McConnel (1965) & $\mathrm{x}$ & & & & $\mathrm{x}$ & \\
\hline McCreery and Claridge (2002) & $\mathrm{x}$ & & & & $\mathrm{x}$ & \\
\hline Ostrow (1960) (cases A, B) & $\mathrm{x}$ & & & & $\mathrm{x}$ & \\
\hline Salama (1981) & $\mathrm{x}$ & $\mathrm{x}$ & & $\mathrm{x}$ & $\mathbf{x}$ & \\
\hline Schmitt (1948) (case 5) & & $\mathrm{x}$ & & & $\mathrm{x}$ & \\
\hline Zutt (1953) & & & $\mathrm{x}$ & & & $\mathrm{x}$ \\
\hline
\end{tabular}

OBEs in healthy subjects (Blackmore, 1986; Röhricht and Priebe, 1997). Moreover, Blackmore (1986) and Röhricht and Priebe (1997) investigated the prevalence of OBEs in schizophrenic and healthy control subjects and found no evidence for a higher prevalence of OBEs in patients suffering from schizophrenia (if compared with healthy control populations). Although, hallucinations such as auditory verbal hallucinations were more frequent (intra-individually) in schizophrenic patients, this was not the case for OBEs (Blackmore, 1986; Röhricht and Priebe, 1997). McCreery (1993) also found no relationship between the occurrence of OBEs and psychiatric illness. Evidence for a relation between psychiatric illness and OBEs was provided by studies investigating the presence of OBEs in healthy subjects as classified by several schizotypy scales. Schizotypy refers to a personality trait in healthy subjects that is characterized by aberrant perceptions and beliefs, cognitive disorganization, introvertive anhedonia, and asocial behavior (Meehl, 1962;
McCreery and Claridge, 1996b). Thus, McCreery and Claridge $(1995,2002)$ found that healthy subjects with $\mathrm{OBE}$ scored higher on a measure of schizotypy ("Aberrant Perceptions and Beliefs") than subjects without OBEs. This was confirmed by Wolfradt and Watzke (1999), who also showed that healthy subjects with OBEs scored higher on a different schizotypy measure (including disorganization, cognitive-perceptual deficits, depersonalization) than subjects without OBEs. It is thus at this point not possible to analyze the phenomenology of OBE in schizophrenic patients and compare them with the phenomenology of neurological patients and healthy subjects. Finally, Reynolds and Brewin (1999) showed that the frequency of OBEs in a group of patients suffering from posttraumatic stress disorder was $42 \%$ and thus characterized by a fourfold increase with respect to the prevalence in healthy subjects.

In conclusion, these data suggest that OBEs occur in psychiatric conditions such as schizophrenia, depression, and posttraumatic stress disorder. 
The presence of autoscopic hallucinations and heautoscopy in psychiatric patients, the increased presence of OBEs in healthy subjects with schizotypy (McCreery and Claridge, 1995, 2002; Wolfradt and Watzke, 1999), depression and posttraumatic stress disorder (Reynolds and Brewin, 1999) suggests that OBEs may also be more frequent in schizophrenic patients than is actually thought. However, we think that further research needs to be conducted in psychiatric patients with OBEs by obtaining precise phenomenological information about the content of the OBE, about the associated illusions and hallucinations (with special reference to vestibular sensations and body schema disturbances) as well as a detailed neuropsychological examination.

\section{Body position}

Most techniques that are used to voluntarily induce OBEs propose that the subjects use a supine and relaxed position (Blackmore, 1982a; Irwin, 1985), suggesting an influence of proprioceptive and tactile mechanisms on OBEs. Interestingly, a supine body position was also reported by all neurological patients with OBEs of Blanke et al. (2004) and in $75 \%$ of healthy subjects with OBEs that were reported by Green (1968). On the contrary, patients with autoscopy or heautoscopy in the study by Blanke et al. (2004) were either in a sitting or standing position. This confirms results by Dening and Berrios (1994) about the body position during autoscopy, who reviewed a large number of patients with autoscopy and heautoscopy. Thus, OBEs seem to depend differently on the subject's position prior to the experience than the other types of autoscopic phenomena suggesting that proprioceptive and tactile mechanisms influence both phenomena differently. Interestingly, for two other main precipitating factors of OBEs-general anesthesia and sleep-subjects are also in supine position corroborating the observation that OBEs are facilitated by the somatosensory coding of a supine body position.

OBEs also seem to occur frequently during rapid bodily position changes such as rapid whole body accelerations and decelerations. OBEs have been reported in these latter situations for a long time such as in falls of mountain climbers (Heim, 1892; Ravenhill, 1913; Habeler, 1979; Brugger et al., 1999; Firth and Bolay, 2004), in car accidents (Muldoon and Carrington, 1929; Devinsky et al., 1989), and more recently also by airplane pilots (Benson, 1999). Thus, the Swiss geologist Albert Heim, who was an amateur mountain climber and who nearly lost his life more than once in mountain climbing accidents, started to collect systematically the accounts from fellow mountain climbers who have also been victims of life-threatening falls (quoted after Ring, 1980, p. 21). In addition, Brugger et al. (1999) have shown that extreme altitude climbing is accompanied by a high incidence of hallucinatory experiences. These authors reported that $75 \%$ of highly specialized extreme-altitude climbers experienced OBEs (especially if climbing above $6000 \mathrm{~m}$ altitude), of which $63 \%$ occurred during acute life-threatening situations (see also Habeler, 1979). Firth and Bolay (2004) reported a case of a mountain climber who experienced an OBE at $6700 \mathrm{~m}$ altitude:

$$
\begin{aligned}
& \text { [...] Descending the mountain, he felt as } \\
& \text { if the person were following him and } \\
& \text { conducted a mental conversation with } \\
& \text { his apparent companion. While walk- } \\
& \text { ing, he felt as if his legs were moving of } \\
& \text { their own accord and his torso was } \\
& \text { elongated. He felt detached from his } \\
& \text { person, as if he were observing himself } \\
& \text { from a distance. He was aware of the } \\
& \text { hallucinatory nature of his experiences. } \\
& \text { These anomalies lasted approximately } \\
& 10 \text { min before disappearing spontane- } \\
& \text { ously [...] }
\end{aligned}
$$

In addition, Brugger et al. (1999) have shown that high-altitude mountain climbing is also associated with reversible neuropsychological deficits, probably due to a number of factors such as cerebral hypoxia, physical exhaustion, hypothermia, food deprivation, dehydration, and sleep deprivation (see below). As stated above, OBEs have also been reported in aviation. Thus, a pilot might fail to sense correctly the position, motion or tilt of the aircraft as well as his own body position with respect to the surface of the earth and the 
gravitational "earth-vertical" (Benson, 1999). It is assumed that this is caused by a vestibular disturbance or failure to signal the extreme motions during aviation. A particular experience reported in these instances is called the "break-off phenomenon" and is highly similar to OBEs. The break-off phenomenon is a cluster of experiences and characterized by feelings of physical separation from the earth, lightness, and an altered perception of the pilot's own orientation with respect to the ground and the aircraft (Clark and Graybiel, 1957; Sours, 1965; Benson, 1999). Some pilots have described a feeling of detachment, isolation, and remoteness from their immediate surroundings, which are sometimes described as an OBE with disembodiment, elevated visuo-spatial perspective, and autoscopy (Tormes and Guedry, 1975; Benson, 1999). Thus, the break-off phenomenon has been described as a feeling of being isolated, detached, or separated physically from the world and the body. Other pilots have described the feeling of being all of a sudden outside the aircraft or outside themselves watching themselves while flying the aircraft, and of being "broken off from reality" (Benson, 1999). These OBEs are most often experienced by jet aviators who are flying alone especially at high altitudes (above $10,000 \mathrm{~m}$ ), although helicopter pilots can experience this phenomenon already at an altitude of 1500-3000 m (Tormes and Guedry, 1975; Benson, 1999). Finally, the breakoff phenomenon is mostly encountered when pilots are relatively unoccupied with flight details (i.e., absorption; Irwin, 1985) and when they are in long cross-country missions over featureless terrain (Clark and Graybiel, 1957).

In conclusion, static body position and dynamic body position changes seem to influence the occurrence of OBEs. Whereas under static conditions, the supine position seems to favor the occurrence of OBEs, vestibular imbalances during falls or rapid decelerations in mountain climbers, jet aviators, or car drivers seem to increase the frequency of $\mathrm{OBEs}$ or $\mathrm{OBE}-\mathrm{like}$ experiences.

\section{Sleep}

The functional relation between sleep (and dreaming) with OBEs has been investigated and discussed by several authors (Muldoon and Carrington, 1951; Blackmore, 1982b, pp. 313-315; Rogo, 1982, pp. 95, 130-149; Irwin, 1985, pp. 16-21, 257-263). Yet, despite these studies, there has not been much work about the neurobiological mechanisms that might link OBEs with sleep and dreaming. This is probably due to the methodology that was used. First, only questionnaires and self-reports were evaluated. Second, this was done often several months or even years after the occurrence of the analyzed OBE. Third, a systematic analysis of OBEs in healthy subjects with respect to sleep stages as defined by EEG recordings has, to our knowledge, not yet been carried out (see below). However, in the following, we have summarized data from studies that have reported correlations between OBEs and sleep, OBEs and dreaming, and OBEs and EEG recordings. This is complemented by the discussion of more recent neuroimaging studies on sleep and dreaming.

With respect to sleep, the aforementioned studies suggested that OBEs are especially frequent in the periods before falling asleep (hypnagogic), resting, or dozing and before waking up (hypnopompic) (Monroe, 1974; Sheils, 1978; Palmer, 1979; Twemlow et al., 1980; Twemlow et al. 1982; Gabbard \& Twemlow 1984; Rogo, 1986; LaBerge, 1990; Alvarado, 2000). In more detail, Greenhouse (1975, p. 91) alleges that most OBEs occur during sleep. In a sample of 122 healthy subjects, Poynton (1975) reports the prevalence of OBEs that occur while "sleeping" at $27 \%$, while "dozing" at $20 \%$, and while "relaxing" at $16 \%$. This was also found by Green (1968), who reported that in $24 \%$ of the subjects with multiple OBEs, at least one OBE started during sleep. Girard and Cheyne (2004) also have reported (in a group of healthy subjects) that OBEs may occur as hypnagogic and hypnopompic hallucinations (among many other experiences). Other authors have tried to provoke OBEs by inducing a hypnagogic-like state (Muldoon and Carrington, 1929; Mitchell, 1973; Monroe, 1974; Baker, 1977; Rogo, 1986). More experimentally, Palmer (1979) has reported that his technique of "progressive muscle relaxation" in combination with the instructions "to relax and to project consciousness to "a place outside one's body" might lead to the occurrence 
of OBE-like experiences in $50 \%$ of his sample of 180 healthy subjects (in comparison to a prevalence of only $10 \%$ under normal conditions). Yet, with respect to all aforementioned studies, it needs to be stressed that the data were mainly collected retrospectively, that the phenomenology of the reported experiences did only rarely correspond to a full-blown OBE (complying with all three variables as described above), and that no EEG data were available. Based on these studies it cannot be stated precisely which of the many sleep variables or which sleep stages are precipitating factors of OBEs. We describe in the following, several recent neuroimaging studies that have investigated the neural correlates of pre-sleep wakefulness (or resting state; Andreasen et al., 1995).
For this we selected several studies that have compared the brain activation between pre-sleep wakefulness with either sleep or cognitive tasks. Thus, Maquet et al. $(1996,1997)$ compared presleep wakefulness with slow-wave sleep (SWS, stages 3 and 4) and rapid-eye movement (REM sleep) by positron emission tomography (PET) and found that the most active cortical brain regions were located in the prefrontal, anterior cingulate, and parietal and precuneal cortices (Fig. 3; adapted from Maquet, 2000; p. 215). Similar results were obtained by Andreasen et al. (1995). They compared a resting state with a memory task and observed that the brain regions that were more active in the resting state were located in the prefrontal and parietal cortex. Both

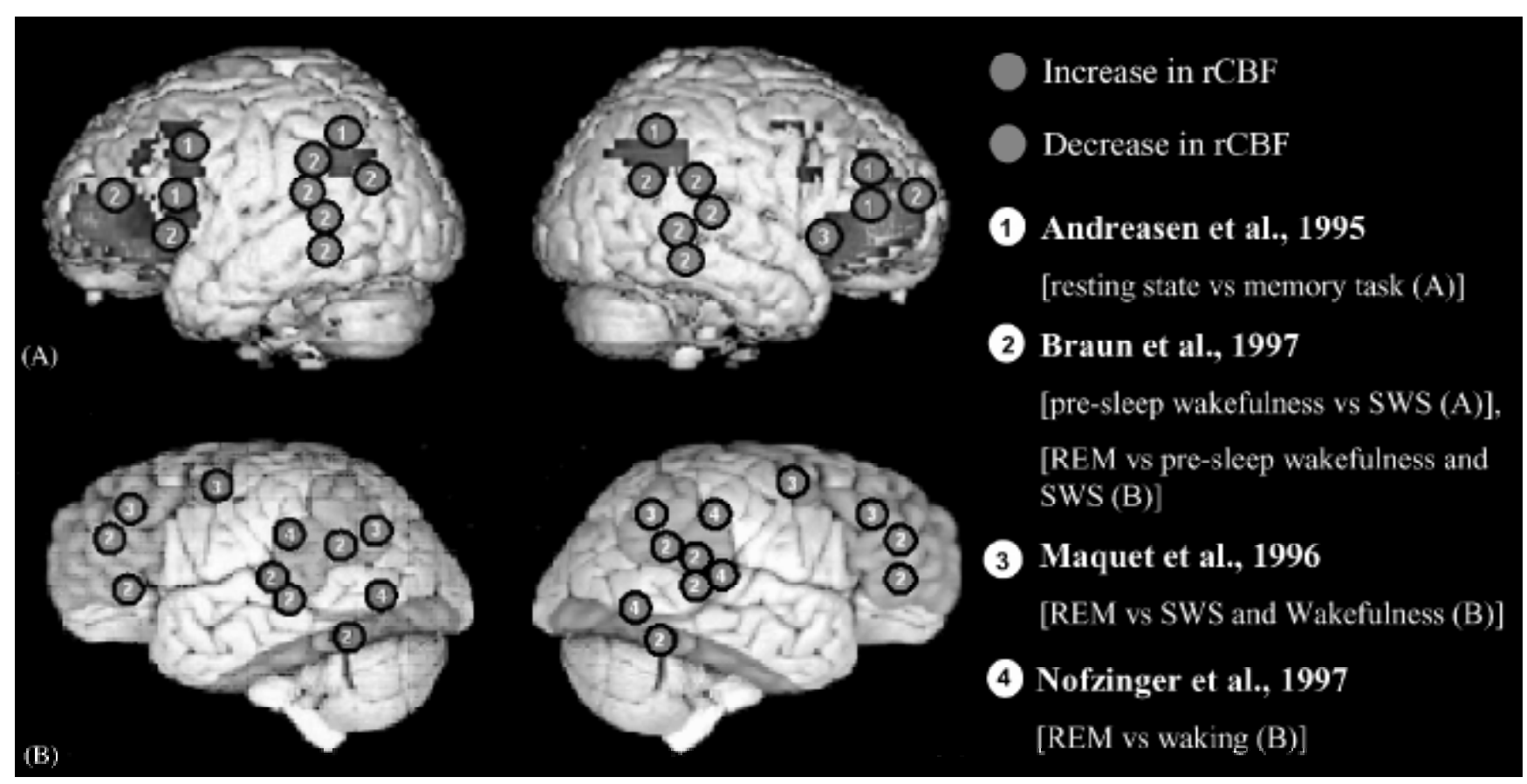

Fig. 3. Regional cerebral blood flow during pre-sleep wakefulness, resting state, and during REM sleep. (A) The figure shows brain activation patterns during pre-sleep wakefulness and resting state compared to sleep (see text). The results of several studies are shown (1, Andreasen et al., 1995; 2, Braun et al., 1997). Estimated peak of activation (red) and deactivation (blue) are plotted on a figure reproduced with permission from Maquet (2000) showing activated brain areas during pre-sleep wakefulness as compared to sleep. The main voxels of activation on the lateral cortical surface are shown. Note the focalization on two lateral cortical areas: prefrontal cortex and TPJ. Whereas the prefrontal cortex is activated during pre-sleep wakefulness, the TPJ is characterized by an activation of the inferior parietal lobule and deactivation of the posterior parts of the superior, middle, and inferior temporal gyri. (B) Schematic representation of the relative increases and decreases in neural activity associated with REM sleep. The figure is modified and reproduced with permission from Schwartz and Maquet (2002). The results of several studies (2, Braun et al., 1997; 3, Maquet et al., 1996; 4, Nofzinger et al., 1997) are plotted. The main voxels of activation on the lateral cortical surface are shown. Red color indicates increases and blue color indicates decreases in rCBF. Brain deactivations focus on the lateral prefrontal cortex and the TPJ. Again, the TPJ shows patterns of activation and deactivation in close proximity. (See text for more details). See Plate 24.3 in Colour Plate Section. 
studies reported equal levels and locations of activations in the right and left hemisphere. All activations were found bilaterally except for prefrontal cortex that was only found in the left hemisphere. Braun et al. (1997) showed that presleep wakefulness as compared to SWS is associated with increases in brain activation in the angular and supramarginal gyri, as well as in prefrontal cortex laterally and medially. Decreases in activation were observed in the posterior lateral temporal lobe (superior, middle, and inferior temporal gyri), the fusiform gyrus as well as striate cortex and the lateral occipital cortex. These findings are summarized in Fig. 3A. Inspection reveals that brain activations focus on two lateral regions, the prefrontal cortex and the TPJ. In addition, brain activation at the TPJ showed patterns of activation and deactivation in close proximity.

With respect to dreaming, several authors have pointed out the connection between OBEs and dreaming (Poynton, 1975; Osis and Mitchell, 1977; Sheils, 1978; Palmer, 1979; Twemlow et al., 1982). Thus, Twemlow et al. (1982) reported that $35 \%$ of subjects who were asked about their mental state at the time of the OBE reported that they were dreaming. Palmer (1979) found a highly significant correlation between having an OBE and having vivid dreams. Finally, Sheils (1978) showed that in $32 \%$ of all cultures that were investigated (from 67 different ethnic groups), OBEs are frequently and habitually connected to dreaming. Again, no EEG data were reported in these studies. Although dreaming also occurs during non-REM sleep, dreams during REM sleep tend to be longer, more easily elicited, more vivid, more emotional, and more coherent (Aserinsky and Kleitman, 1953; Rechtschaffen and Siegel, 2000; Nielsen, 2003). In the following we will thus review some recent studies on the functional neuroanatomy of REM sleep (and dreaming) if compared with SWS or wakefulness. During REM sleep, Maquet et al. (1996, 1997) found significant and widespread cortical activations when compared to SWS. These authors used PET and described REM sleeprelated activations in limbic areas (amygdaloid complexes, hippocampal formation, and anterior cingulate cortex) and the cortex (bilateral striate cortex, temporo-occipital cortex, extrastriate cortex, motor and premotor as well as superior parietal lobule). In contrast, the dorsolateral prefrontal cortex, inferior parietal lobule (supramarginal gyrus) as well as posterior cingulate cortex and precuneus were deactivated. The findings of Nofzinger et al. (1997) corroborate these results (REM sleep versus waking). Braun et al. (1997) found more focal REM sleep activations and compared REM sleep with SWS and pre-sleep wakefulness. They found activations of extrastriate cortex, particularly within the ventral processing stream, and an attenuation of activity in the striate cortex. In addition, increases in regional cerebral blood flow (rCBF) in extrastriate areas were significantly correlated with decreases in the striate cortex. Extrastriate activity was also associated with concomitant activation of limbic and paralimbic regions, but with a marked reduction of activity in frontal association areas including lateral orbital and dorsolateral prefrontal cortices. These findings have been reviewed by Schwartz and Maquet (2002) and are summarized graphically in Fig. 3B. Note that brain activations again focus on the lateral prefrontal cortex and the TPJ. Again, the TPJ showed patterns of activation and deactivation in close proximity. Also note that these data suggest that the prefrontal cortex was mainly activated during pre-sleep wakefulness (Fig. 3A), whereas it was mainly deactivated during REM sleep.

With respect to the relationship between OBEs and sleep or dreaming, we noted that none of the aforementioned questionnaire or self-report studies recorded EEG variables in their subjects neither between nor during OBEs. Yet, the EEG is necessary in order to define the different sleep stages (Rechtschaffen and Siegel, 2000). Furthermore, with respect to EEG recordings during OBEs several methodological difficulties exist. These are due to the nature of OBEs, which are usually short lasting and occur spontaneously. In addition, in the large majority of subjects they happen only once or twice in a lifetime (Blackmore, 1982a; Irwin, 1985). It is thus extremely difficult to have the opportunity to record an EEG during an OBE. Finally, there are methodological problems as to the temporal definition of the onset and offset of an OBE and how subjects are to indicate this to 
the investigator in order to interfere with the mental state of the investigated subject as least as possible. Nevertheless, several authors have tried to record EEGs during OBEs in several subjects that were known to experience OBEs frequently and claim to be able to induce OBEs voluntarily (OBE adepts).

Tart $(1967,1968)$ was the first to investigate EEG activity during OBEs. Although in his first study, Tart (1967) was able to record EEG during three OBEs, these OBEs did not reflect the subject's habitual OBEs. In addition, the patient reported sensations of floating in and out of her body (first and third OBE), sensations of flying and experiential phenomena (second OBE), but no autoscopy (all OBEs), and did not mention an elevated visuo-spatial perspective explicitly (first two OBEs). OBEs occurred during an EEG pattern between sleep and wakefulness characterized by a poorly developed "unusual" alpha-like pattern (slower than the normal rhythm) associated additionally with EEG flattening, low voltage spindles, and transitory periods of wakefulness. In his second study, Tart (1968) recorded the EEG during two full-blown OBEs of the OBE-adept Robert Monroe (Monroe, 1974). No significant abnormality was seen in Monroe's standard and sleep EEG and the investigated OBEs were reported to be associated in the EEG with REM sleep followed by awakening and body movements. Janis et al. (1973) recorded EEG in the OBE-adept Blue Harary and found no EEG differences during the OBE period if compared to OBE-free periods. No phenomenological detail about the OBE was given. Hartwell et al. (1974) further investigated the EEG recorded from Blue Harary (Blackmore, 1982a). They analyzed alpha density and EEG frequency, but again, no differences were found between OBE and OBE-free periods. The standard EEG of Blue Harary during the OBE was also described as normal. No phenomenological detail about the OBE was given. Osis and Mitchell (1977) recorded the EEG in the OBE-adept Ingo Swann (Blackmore, 1982a). The authors describe that the OBE was associated with a diminished EEG amplitude and that, in general, the duration of alpha was diminished in Ingo Swann's EEG recording. No phenomenological detail about the
OBE was given. Twemlow (1977) recorded Robert Monroe's EEG during one full-blown OBE and reported a general slowing down of the EEG during the OBE stating that they observed no EEG rhythms faster than $10 \mathrm{~Hz}$ during the OBE period. Finally, they mentioned EEG right-left asymmetries during the OBE.

In conclusion, these studies did not allow to describe a specific EEG pattern or sleep stage in association with OBEs in this group of OBE adepts (see also Irwin, 1985). Flattening, faster EEG rhythms, as well as slowing, and sub-alpha EEG patterns, right-left asymmetries, or no EEG differences between OBE- and OBE-free periods were described. OBEs occurred either during sleep or wakefulness. In addition, it should be mentioned that most of these studies were done quite some time ago and recorded only with few electrodes allowing to define sleep stages, but not the recording and determination of EEG patterns, their localization, and lateralization with enough spatial precision. Nevertheless, these studies point to the feasibility of a scientific approach in order to investigate the association of OBEs with certain EEG measures and sleep. In our opinion, future studies should ideally investigate subjects with fullblown OBEs and use EEG recordings with at least 32 scalp electrodes to allow lateralization and localization of EEG patterns or even the localization of their brain generators (Michel et al., 2004). Also, systematic approaches need to be used in order to determine as unambiguously as possible the onset and offset of the OBE. Finally, it might be possible to carry out experimental studies in normal subjects in whom OBEs can be more systematically induced by a given procedure allowing to perform multichannel EEG recordings in larger subject groups as pioneered by Palmer (1979) and McCreery and Claridge (1996a).

\section{Drugs}

Drug abuse including marijuana, opium, heroin, mescaline or lysergic acid diethylamide (LSD), has been reported to be associated with a higher prevalence of autoscopic phenomena such as OBEs (i.e., Tart, 1971; Blackmore, 1982a; Aizenberg and 
Modai, 1985; Grüsser and Landis, 1991; Shermer, 1998). In addition, hallucinogens have long been used intentionally in various cultures to induce OBE-like states (Sheils, 1978). In an exemplary fashion, for the present review, we will focus on marijuana ( $\delta$-9-tetrahydrocannabinol) and its relation to OBEs and its neural mechanisms.

With respect to marijuana, Tart (1971) reported an OBE prevalence of $44 \%$ among people with varying abuse of marijuana, whereas OBEs only occur in about $10 \%$ in the general population (Irwin, 1985, pp. 174-175; Alvarado, 1986). This questionnaire study was carried out in a sample of 150 college students and the presence of an OBE was defined as the feeling that the subject "felt located outside the physical body" (no full-blown OBE as described in the present article). Moreover, Tart (1970) mentions that the majority of all OBE cases were observed in subjects that had used marijuana frequently (more than once a week or daily) and also had experience with more powerful psychoactive drugs such as LSD (even in the 6month period preceding the questionnaire study). A small sample had even used hard narcotics or dangerous stimulants (also see Irwin, 1985, p. 209). Thus it cannot be stated whether the high frequency of OBEs in this subject sample was due to the effects of marijuana or the effects of these other drugs. Further evidence that marijuana increases the occurrence of OBEs comes from Siegel (1977). Siegel (1977) administered either marijuana or placebo in a controlled experiment and directly questioned both subject groups about their experiences. Although subjects mostly reported simple visual illusions and hallucinations, some subjects of the marijuana group reported OBE-like experiences such as a feeling of being dissociated from their body, a feeling of floating, and a realistic impression of a surround view. Finally, given that surveys of the general population have obtained a OBE-prevalence of $10 \%$ and of $25 \%$ in college students (Irwin, 1996), Palmer (1979) has suggested that this increase might be due to the higher use of mind-altering drugs by students.

Although, the influence of marijuana on the OBEs has to our knowledge only been investigated in these two studies, they suggest that marijuana use increases the probability of experiencing an
OBE. Given this probable relation and the fact that the use of marijuana may result in an alteration of sensory, motor, and cognitive functions (Block et al., 1992), we have summarized below several neuroimaging studies that have examined the effect of marijuana administration on brain metabolism. Although over 60 cannabinoids have been identified in the plant Cannabis sativa, $\delta$-9-tetrahydrocannabinol (THC) appears to be the major psychoactive ingredient of marijuana. In the following we summarize neuroimaging studies that have used THC. Thus, Mathew et al. (1997) described PET data in 32 volunteers before and after intravenous infusion of THC or placebo. THC resulted in increased $\mathrm{rCBF}$ bilaterally in the frontal lobes, the insula, anterior cingulum, temporal lobes and in subcortical regions, with the largest effects in the right hemisphere. Volkow et al. (1996) described the cerebral metabolic changes induced by THC in eight chronic users of marijuana compared to non-users of marijuana. Even without the administration of marijuana, the group of chronic marijuana users had significantly less relative metabolic activity in the cerebellum than did normal control subjects. After smoking marijuana, cerebellar activity was increased in both groups, but only the group of chronic marijuana users showed additional significant increases in orbitofrontal, prefrontal cortex, and basal ganglia. A PET study carried out by O'Leary et al. (2000) measured rCBF prior to and following smoking marijuana while subjects were engaged in an auditory attention task. This study of five subjects found that smoking marijuana increases rCBF in a number of paralimbic regions (orbital frontal lobes, insula, temporal poles) and in the anterior cingulated cortex, and the cerebellum. Large reductions in $\mathrm{rCBF}$ were observed in the temporal lobe regions. A more recent study by O'Leary et al. (2002) involved a sample of 12 volunteers, who were occasional smokers of marijuana. Again a PET study was carried out before and after smoking, and the smoking of marijuana was associated with increased $\mathrm{rCBF}$ in the temporal lobe, prefrontal lobe, insula, and the cerebellum. Regions with lower rCBF were observed in prefrontal cortex, in the superior temporal gyrus, and the occipital lobe. In summary, the present data 
suggest that, although the prevalence of OBEs increases by marijuana use, other visual illusions and hallucinations increase more strongly. Secondly, the observed brain activations were focused on the cerebellum and were at the neocortical level quite widespread without focalization. No significant activations were found at the TPJ.

\section{General anesthesia}

It has also been reported that general anesthesia is a common precipitating factor of OBEs. This was first stated by Muldoon and Carrington (1951) and confirmed by Crookall (1964). These authors collected many cases of OBEs from the first half of the 20th century following the introduction of general anesthesia into medicine. Yet, although Crookall (1964) reported 21 OBE cases (cases 347-365; pp. 98-108), only 11 comply with the OBE criteria as defined in the present article. Several other experiences classified by Crookall (1964) as OBEs in the context of general anesthesia were unspecific feelings of dissociation, other autoscopic phenomena, or the feeling of somebody closeby. The following example (containing the three defining features of the OBE: disembodiment, elevated visuo-spatial perspective, and autoscopy) is taken from Muldoon and Carrington (1951; quoted after Blackmore, 1982a):

I saw myself- my physical self- lying there. I saw a sharply outlined view of the operating table. I myself freely hovering and looking downward from above, saw my physical body, lying on the operating table. I could see the wound of the operation on the right side of my body, see the doctor with instrument in his hand, which I cannot more closely describe. All this I observed very clearly. I tried to hinder it all. It was so real. I can still hear the words I kept calling out: Stop itwhat are you doing there?

Although these early case collections suggest that OBEs may occur in patients undergoing general anesthesia, it is not known what types of anesthetics lead to OBEs, whether only selective patient subgroups might suffer from OBEs during general anesthesia, or whether specific operations are associated with OBEs. Moreover, the aforementioned case collections did not inquire about other experiences during general anesthesia and how frequent awareness (including OBEs) was during general anesthesia. Finally, as stated above for the case collection by Crookall (1964) not all patients reported as OBE cases experienced an OBE that complied with the definition of an OBE that was used in the present article.

"Awareness during anesthesia is as old as the specialty itself" (Spitellie et al., 2002) and is generally thought to be due to two main factors. First, lack of experience with the new therapeutics in the first half of the 20th century. Secondly, the introduction of muscle relaxants in general anesthesia since 1942. Although this has allowed to use lower doses of toxic anesthetic agents, it increased the difficulty in monitoring the patient's level of consciousness and thus increased the risk of awareness due to insufficient levels of anesthesia (Blacher, 1975; Spitellie et al., 2002). Although the true incidence of awareness is not known, it was estimated between 0.1 and $0.2 \%$ in non-cardiac, nonobstetric, and non-traumatic surgery (Sandin et al., 2000; Spitellie et al., 2002; Sandin, 2003). Much higher incidences of awareness have been reported for caesarean section $(0.4 \%)$, cardiac surgery $(1.5 \%)$, and surgical treatment for trauma $(11-43 \%)$. Moreover, several of these authors have investigated the medical reasons for awareness and, in addition, questioned their patients immediately after their operation about the phenomenological contents of awareness (Blacher, 1975; Cobcroft and Forsdick, 1993; Moermann et al., 1993; Ranta et al., 1998; Ostermann et al., 2001). Blacher (1975) reported five patients with awareness during anesthesia, who received muscle relaxants. Moermann et al. (1993) found increased cardiovascular abnormalities during general anesthesia such as heart beat acceleration and blood pressure increase (probably indicating insufficient anesthesia) in $67 \%$ of patients with awareness during anesthesia. In comparison, these intraoperative cardiovascular abnormalities were only found in $21 \%$ of patients without awareness during anesthesia. Sandin et al. (2000) performed a 
study of 11,785 patients and found a higher incidence of awareness if muscle relaxants were used. In addition, technical problems during anesthesia were responsible for insufficient anesthesia in 50\% of patients suffering from awareness during anesthesia (Sandin et al., 2000). These studies have also shown that in principle all anesthetics independently of their administration (oral, intravenous, and inhalatory) may lead to awareness speaking against a special role for certain anesthetics in the induction of OBEs and related experiences (i.e., Ketamin) (Jansen, 1989, 1997). In summary, insufficient levels of anesthesia in combination with the application of muscle relaxants seem to be the main cause of awareness during anesthesia. Yet, effects of hemodynamic instability on the central nervous system during surgery also seem to be another important pathophysiological factor since awareness during anesthesia in patients undergoing cardiac and traumatic surgery has a very high incidence (i.e., almost every third patient) and is often associated with hemodynamic instability (Gurman et al., 2002; Spitellie et al., 2002; Sandin, 2003).

With respect to the phenomenological content of the period of awareness during anesthesia, Moermann et al. (1993) found that most reported experiences are auditory perceptions $(89 \%)$ as well as somatosensory or motor perceptions such as the sensations of paralysis (85\%), pain (39\%), bodily movements, and bodily modifications (30-40\%; Cobcroft and Forsdick, 1993; Moermann et al., 1993). The presence and relative distribution of these perceptions have been confirmed by other authors (Ranta et al., 1998; Ostermann et al., 2001). Visual perceptions and OBEs are thus quite rare perceptions during general anesthesia. Whereas it is not possible to decide whether any of Blacher's patients (1975) experienced OBEs during periods of surgical awareness, Moermann et al. (1993) reported visual experiences in $27 \%$ of their patients including several instances during which patients experienced to see the surgeon and other people and/or surroundings of the operating theatre during the actual operation. Yet, it is not mentioned whether any of the patients presented any of the three defining features of OBEs (disembodiment, elevated visuo-spatial perspective, and autoscopy). The experience of patient 3 of Ranta et al. (1998) might be classified as an OBE as she reported that she saw the "light of the operating room and people operating on her" (i.e., explicit autoscopy), but there is no mentioning of disembodiment or elevated visuo-spatial perspective. A full-blown $\mathrm{OBE}$ is reported by Cobcroft and Forsdick (1993) in four of a total of 187 analyzed cases (i.e., $2 \%$ ) of which one example is given here:

I had the strangest [...] sensation of coming out of my self; of being up at the ceiling looking down on the proceedings [of the operation]. After the initial realization that I couldn't communicate at all, came the feeling of acceptance ... of being aware of having one hell of an experience.

Other patients of Cobcroft and Forsdick (1993) reported sensations of moving in a tunnel, of seeing faces, of seeing operating theatre details, as well as seeing bright lights and surrounding whiteness (4\% of all evaluated patients). Several of Osterman et al.'s patients (2001) reported that they "left their body during the operation at some point". Thus, OBEs are not very frequent in patients undergoing general anesthesia. Yet, if analyzed only with respect to the reported visual experiences during general anesthesia, OBEs and OBE-like experiences are very frequent. Finally, the sensations of paralysis as well as of bodily movements and modifications are not only frequent in awareness during general anesthesia, but also frequently reported by subjects with OBEs of spontaneous or neurological origin (Blackmore, 1982a; Irwin, 1985; Blanke et al., 2004).

In summary, these data suggest that although visual awareness is rare during general anesthesia, many of such visual perceptions are full-blown OBEs or related experiences. The partial awareness of patients during general anesthesia, in association with the frequent sensations of paralysis, bodily movements, and bodily modifications, as well as the patient's supine body position have also been described in OBEs of neurological origin. Hemodynamic instabilities such as during cardiovascular and traumatic surgery (with much higher 
incidences of awareness) might be a second precipitating factor for OBEs in general anesthesia. It has been shown that hemodynamic instabilities during these operations may lead to decreases in cerebral blood perfusion and may have, as a consequence, transient or manifest low-flow brain infarctions (or borderzone infarctions). It is interesting to note that these frequently include the TPJ (Ringelstein and Zunker, 1998) suggesting that OBEs under general anesthesia might be related to the functional and anatomical pathomechanisms as described in neurological patients with epilepsy, migraine, and cerebrovascular disease.

\section{Cognitive neuroscience of OBE and self}

The above findings suggest that OBEs are related to states of partially impaired consciousness (i.e., hypnopompic or hypnagogic states; dreaming; complex partial seizures, migraine) or a state of partially conserved awareness under general anesthesia as proposed previously (Tart, 1974, p. 370; Tart, 1975, pp. 71-72; Blackmore, 1982a). Importantly, these clinical and neuroimaging findings have allowed to link the complex phenomenon of the OBE with multisensory disintegration and deficient own body processing at the TPJ. This is not trivial as these findings may help to demystify OBEs and facilitate the formulation of precise research hypotheses about the sensory, cognitive, and neural mechanisms of OBEs. The neuroscientific investigation of OBEs may also turn out to be very useful in defining some of the functions and brain structures mediating such aspects of the normal self such as corporeal awareness, embodiment, egocentric visuo-spatial perspective, and self-consciousness (Metzinger, 2003, in press; Blanke and Arzy, 2005). In the following we will review recent neuroimaging data about the TPJ's implication in self and corporeal awareness.

Neuroimaging studies support the role of the TPJ in vestibular processing, multisensory integration as well as the perception of human bodies or body parts. First, the core region of the human vestibular cortex (Lobel et al., 1998; Fasold et al., 2002) is situated at the TPJ including the posterior insula. Brain damage in this area has been associated with vestibular sensations and dysfunctions (Smith, 1960; Brandt, 2000). Second, several neuropsychological and neuroimaging studies suggest the implication of the TPJ and cortical areas along the intraparietal sulcus in combining tactile, proprioceptive, and visual information in a coordinated reference frame (Calvert et al., 2000). Interestingly, Leube et al. (2003) have shown that the TPJ codes multisensory conflict between visual and proprioceptive information about one's arm position as proposed in the above OBE-model for the entire body. Third, the TPJ is also involved in the perception of many different aspects of the human body including the perception of body parts (Bonda et al., 1995), the entire body (Downing et al., 2001; Astafiev et al., 2004) as well as biological motion (Grossman et al., 2000; Beauchamp et al., 2002) and mental imagery with respect to one's own body (Zacks et al., 2002; Blanke et al., 2005). Importantly, Astafiev et al. (2004) have shown that some of these "visual" areas are not only modulated by visually presented human bodies or body parts, but also by limb movements (without visual feedback) suggesting their role in multisensory own body perception.

The TPJ has also been involved in cognitive functions that are closely linked to self processing and OBEs: egocentric visuo-spatial perspective taking (Farrell and Robertson, 2000), agency (the feeling of being the agent of one's actions and thoughts; Chaminade and Decety, 2002; Farrer and Frith, 2002; Farrer et al., 2003), and self-other distinction (the capacity by which one distinguishes between oneself and other conspecifics; Ruby and Decety, 2001, 2003, 2004; Chaminade and Decety, 2002; Farrer et al., 2002, 2003). Thus, during OBEs one's visuo-spatial perspective and one's sense of agency are localized at the position of the disembodied self that is hovering above the physical body. In other words, the self is experienced as looking at the (autoscopic) body from a third (or other) person's visuo-spatial perspective and position. Furthermore, the TPJ is the classical lesion site in patients with visuo-spatial neglect (Halligan et al., 2003), a clinical condition, which has been shown to disturb the patient's egocentric spatial relationship with extracorporeal space and visuo-spatial perspective taking (i.e., Farrell and 
Robertson, 2000). Neuroimaging studies in healthy observers have also revealed activation of the TPJ during egocentric visuo-spatial perspective changes in healthy subjects (Maguire et al., 1998; Ruby and Decety, 2001). Moreover, it has been shown that mental activities such as agency and self-other distinction activate the TPJ (Ruby and Decety, 2001, 2003, 2004). In another study, Perrin et al. (2005) have shown by measuring $\mathrm{rCBF}$ and evoked potentials that subjects' own name or names from other people activated the TPJ. In a recent study, Blanke et al. (2005) have used a mental imagery task with respect to one's own body and linked essential phenomenological characteristics of the OBE to the TPJ. They asked healthy subjects to imagine themselves in the position and visual perspective that is generally reported by people experiencing spontaneous OBEs and found an activation of the TPJ. Interference with the TPJ by transcranial magnetic stimulation impaired mental transformation of the own body in healthy volunteers, but not for imagined spatial transformations of external objects suggesting the selective implication of the TPJ in mental imagery of one's own body (Blanke et al., 2005). Finally these authors showed, in an epileptic patient with OBEs originating from the TPJ, partial activation of the seizure focus during mental transformations of her body and visual perspective mimicking her OBE percepts. Based on these results, Blanke et al. (2005) argued that the TPJ might be a crucial structure for the conscious experience of the normal self mediating spatial unity of self and body and that impaired processing at the TPJ may lead to the experience of abnormal selfs, such as OBEs.

In summary, although many other cortical areas such as prefrontal, anterior cingulate, postcentral, precuneal, occipito-temporal junction, superior parietal lobule, and insular cortices (Grossman et al., 2000; Ruby and Decety, 2001, 2003, 2004; Beauchamp et al., 2002; Chaminade and Decety, 2002; Zacks et al., 2002; Leube et al., 2003) have been shown to play a role in self processing, the reviewed neuroimaging data on body and self processing as well as the clinical data on OBEs suggest that the TPJ is a key neural locus for self processing that is involved in multisensory bodyrelated information processing as well as in processing of phenomenological and cognitive aspects of the self.

\section{Conclusions}

OBEs have fascinated mankind from time immemorial and are abundant in folklore, mythology, and spiritual experiences of most ancient and modern societies. We have reviewed clinical and neuroimaging evidence suggesting that OBEs are culturally invariant brain phenomena that have specific precipitating factors and that can be investigated neuroscientifically. The reviewed data on the precipitating factors sleep and general anesthesia in the normal population suggest that OBEs are linked to situations that are associated with partial impairments of consciousness, supine body position, and disturbed own body processing. This fits with the reviewed neurological data where OBEs were observed in patients with partially impaired consciousness in paroxysmal brain dysfunctions (such as epilepsy, migraine, and electrical cortical stimulation), supine body position, and disturbed own body processing. Based on these data we have suggested previously that OBEs might be caused by a functional disintegration in lower-level multisensory processing (vestibular, proprioceptive, tactile, and visual information). Finally, the reviewed data suggest an interaction of lower-level multisensory processing with higherlevel self processing such as egocentric visuo-spatial perspective taking, agency, and self location (or embodiment). From an anatomical point of view, the reviewed data in neurological patients, patients under general anesthesia, and neuroimaging studies on sleep as well as cognitive neuroscience point to the importance of the right TPJ in the generation of OBEs, although the left TPJ as well as other brain areas have also been associated with OBEs. It is hoped that the experimental investigations of the interactions between these multisensory and cognitive systems in OBEs and related illusions in combination with neuroimaging and behavioral techniques will further our understanding of the central mechanisms of self and corporal awareness much as previous research into the neural bases of complex body part illusions has 
demystified phantom limbs (Ramachandran and Hirstein, 1998; Halligan, 2002).

\section{Acknowledgments}

The authors are supported by the "Fondation Leenaards" and the "Fondation de Famille Sandoz."

\section{References}

Aizenberg, D. and Modai, I. (1985) Autoscopic and drug induced perceptual disturbances. A case report. Psychophatology, 18: 97-111.

Alvarado, C.S. (1986) ESP during spontaneous out-of-body experiences: a research and metholodical note. J. Soc. Psychical Res., 53: 393-397.

Alvarado, C.S. (2000) Out-of-body experiences. In: Cardeña E., Lynn S.J. and Krippner S. (Eds.), Varieties of Anomalous Experiences. American Psychological Association, Washington, DC, pp. 183-218.

Andreasen, N.C., O'Leary, D.S., Cizadlo, T., Arndt, S., Rezai, K., Watkins, G.L., Boles Ponto, L.L. and Hichwa, R.D. (1995) Remembering the past: two facets of episodic memory explored with positron emission tomography. Am. J. Psychiatry, 152: 1576-1585.

Arenz, D. (2001) Heautoskopie. Doppelgängerphänomen und seltene Halluzinationen der eigenen Gestalt. Der Nervenarzt, 72: 376-379.

Aserinsky, E. and Kleitman, N. (1953) Regularly occurring periods of eye motility and concomitant phenomena during sleep. Science, 118: 273-274.

Astafiev, S.V., Stanley, C.M., Shulman, G.L. and Corbetta, M. (2004) Extrastriate body area in human occipital cortex responds to the performance of motor actions. Nat. Neurosci., 7: 542-548.

Baker, D.M. (1977) Practical Techniques of Astral Projection. Aquarian Press, Wellingborough, England.

Beauchamp, M.S., Lee, K.E., Haxby, J.V. and Martin, A. (2002) Parallel visual motion processing streams for manipulable objects and human movements. Neuron, 34: 149-159.

Benson, A.J. (1999) Spatial disorientation - common illusions. In: Ernsting J., Nicholson A.N. and Rainford D.J. (Eds.), Aviation Medicine (3rd ed.). Butterworth \& Heinmann, Oxford, pp. 437-454.

Blacher, R.S. (1975) On awakening paralyed during surgery - a syndrome of traumatic neurosis. J. Am. Medi. Assoc., 234(1): 67-68.

Blackmore, S.J. (1982a) Beyond the Body. An Investigation of Out-of-Body Experiences. Heinemann, London.

Blackmore, S.J. (1982b) OBEs, lucid dreams and imagery: two surveys. J. Am. Soc. Psychical Res., 76: 301-317.
Blackmore, S.J. (1986) Out-of-body experiences in schizophrenia. A questionaire survey. J. Nerv. Ment. Disease, 174: 615-619.

Blanke, O. (2004) Illusions visuelles. In: Safran A.B., Vighetto A., Landis T. and Cabanis E. (Eds.), Neuro-opthalmologie. Masson, Paris, pp. 147-150.

Blanke, O. and Arzy, S. (2005) The out-of body experience. Disturbed self processing at the temporo-parietal junction. Neuroscientist, 11: 16-24.

Blanke, O., Landis, T., Spinelli, L. and Seeck, M. (2004) Outof-body experience and autoscopy of neurological origin. Brain, 127: 243-258.

Blanke, O., Mohr, C., Michel, C.M., Pascual-Leone, A., Brugger, P., Landis, T., Seeck, M. and Thut, G. (2005) Linking out-of-body experience and self processing to the temporo-parietal junction. J. Neurosci, 25: 550-557.

Blanke, O., Ortigue, S., Landis, T. and Seeck, M. (2002) Stimulating illusory own-body perceptions. Nature, 419: 269-270.

Block, R.I., Farinpour, R. and Braverman, K. (1992) Acute effects of marijuana on cognition: relationships to chronic effects and smoking techniques. Pharmacol. Biochem. Behav., 43(3): 907-917.

Bonda, E., Petrides, M., Frey, S. and Evans, A. (1995) Neural correlates of mental transformations of the body-in-space. Proc. Natl. Acad. Sci. USA, 92: 11180-11184.

Brandt, T. (2000) Central vestibular disorders. In: Vertigo. Its Multisensory Syndromes. Springer, London, pp. 146-167.

Braun, A.R., Balkin, T.J., Wesensten, N.J., Carson, R.E., Varga, M., Baldwin, P., Selbie, S., Belenky, G. and Herscovitch, P. (1997) Regional cerebal blood flow throughout the sleep-wake cycle. An H215O PET study. Brain, 120: 1173-1197.

Brugger, P. (2002) Reflective mirrors: perspective taking in autoscopic phenomena. Cogn. Neuropsychiatr., 7: 179-194.

Brugger, P., Regard, M. and Landis, T. (1997) Illusory reduplication of one's own body: phenomenology and classification of autoscopic phenomena. Cogn. Neuropsychiatr., 2: 19-38.

Brugger, P., Regard, M., Landis, T. and Oelz, O. (1999) Hallucinatory experiences in extreme-altitude climbers. Neuropsychi. Neuropsy. Behav. Neur., 12: 67-71.

Calvert, G.A., Campbell, R. and Brammer, M.J. (2000) Evidence from functional magnetic resonance imaging of crossmodal binding in the human heteromodal cortex. Curr. Biol., 10: 649-657.

Chaminade, T. and Decety, J. (2002) Leader or follower? Involvement of the inferior parietal lobule in agency. Neuroreport, 13(15): 1975-1978.

Clark, B. and Graybiel, A. (1957) The break-off phenomenon. A feeling of separation from the earth experienced by pilots at high altitude. J. Aviation Med., 28: 121-126.

Cobcroft, M.D. and Forsdick, C. (1993) Awareness under anesthesia: the patients' point of view. Anaesth. Intens. Care, 21: 837-843.

Craske, S. and Sacks, B.I. (1969) A case of "double autoscopy". Br. J. Psychiatr., 115: 343-345.

Crookall, R. (1964) More Astral Projections. Analyses of Case Histories. Aquarian Press, London. 
Daly, D.D. (1958) Ictal affect. Am. J. Psychiatr., 115: 171-181.

Damas Mora, J.M.R., Jenner, F.A. and Eacott, S.E. (1980) On heautoscopy or the phenomenon of the double: case presentation and review of the literature. Br. J. Med. Psychol., 53: 75-83.

Dening, T.R. and Berrios, G.E. (1994) Autoscopic phenomena. Br. J. Psychiatry, 165: 808-817.

Devinsky, O., Feldmann, E., Burrowes, K. and Bromfeld, E. (1989) Autoscopic phenomena with seizures. Arch. Neurol., 46: 1080-1088.

Downing, P.E., Jiang, Y., Shuman, M. and Kanwisher, N. (2001) A cortical area selective for visual processing of the human body. Science, 293: 2470-2473.

Farrell, M.J. and Robertson, I.H. (2000) The automatic updating of egocentric spatial relationships and its impairment due to right posterior cortical lesions. Neuropsychologia, 38: 585-595.

Farrer, C. and Frith, C.D. (2002) Experiencing oneself vs another person as being the cause of an action: the neural correlates of the experience of agency. Neuroimage, 15(3): 596-603.

Farrer, C., Franck, N., Georgieff, N., Frith, C.D., Decety, J. and Jeannerod, M. (2003) Modulating the experience of agency: a positron emission tomography study. Neuroimage, 18(2): 324-333.

Fasold, O., von Brevern, M., Kuhberg, M., Ploner, C.J., Villringer, A. and Lempert, T. (2002) Human vestibular cortex as identified with caloric stimulation in functional magnetic resonance imaging. Neuroimage, 17: 1384-1393.

Firth, P.G. and Bolay, H. (2004) Transient high altitude neurological dysfunction: an origin in the temporoparietal cortex. High Altitude Med. Biol., 5: 71-75.

Gabbard, G.O. and Twemlow, S.W. (1984) With the Eyes of the Mind: An Empirical Analysis of Out-of-Body States. Praeger Scientific, New York.

Gallagher, S. (2000) Philosophical conceptions of the self: implications for cognitive science. Trends Cogn. Sci., 4: 14-21.

Girard, T.A. and Cheyne, J.A. (2004) Individual differences in lateralization of hallucinations associated with sleep paralysis. Laterality: asymmetries of body. Brain Cognit., 9(1): 93-111.

Green, C.E. (1968) Out-of-Body Experiences. Hamish Hamilton, London.

Greenhouse, H.B. (1975) The Astral Journey. Doubleday, Garden City, NY.

Grossman, E., Donnelly, M., Price, R., Pickens, D., Morgan, V., Neighbor, G. and Blake, R. (2000) Brain areas involved in perception of biological motion. J. Cogn. Neurosci., 12: $711-720$

Grüsser, O.J. \& Landis, T. (1991) The splitting of 'I' and 'me': heautoscopy and related phenomena. In: Grüsser, O.J., Landis, T. (General Editor: J.R. Cronly Dillon), Visual Agnosias and Other Disturbances of Visual Perception and Cognition. Macmillan, Amsterdam, pp. 297-303.

Gurman, G.M., Weksler, N. and Schily, M. (2002) Should disclosure of the danger of awareness during general anesthesia be a part of preanesthesia consent? Anesthesia, 68: 905-910.
Habeler, P. (1979) The Lonely Victory. Simon \& Shuster, New York, pp. 166-176.

Halligan, P.W. (2002) Phantom limbs: the body in mind. Cogn. Neuropsychiatr., 7: 251-268.

Halligan, P.W., Fink, G.R., Marshall, J.C. and Vallar, G. (2003) Spatial cognition: evidence from visual neglect. Trends Cogn. Sci., 7: 125-133.

Hartwell, J., Janis, J. and Harary, S.B. (1974) A study of the physiological variables associated with out-of-body experiences. In: Morris J.D., Roll W.G. and Morris R.L. (Eds.), Research in Parapsychology 1974. Scarecrow Press, Metuchen, NJ, pp. 127-129.

Hécaen, H. and Ajuriaguerra, J. (1952) L'heautoscopie. In: Hécaen H. and Ajuriaguerra J. (Eds.), Meconnaissances et Hallucinations Corporelles. Masson, Paris, pp. 310-343.

Hécaen, H. and Green, A. (1957) Sur l'héautoscopie. Encephale, 46: 581-594.

Heim, A. (1892) Notizen über den Tod durch Absturz. Jahrbuch des Schweizer Alpenklub, 27: 327-337.

Irwin, H.J. (1985) Flight of Mind: A Psychological Study of the Out-of-Body Experience. The Scarecrow Press, Inc., Metuchen, NJ.

Irwin, H.J. (1996) Childhood antecedents of the out-of-body experience and déjà vu experiences. J. Soc. Psychical Res., 90: 157-173.

Janis, J., Hartwell, J., Harary, S.B., Levin, J. and Morris, R.L. (1973) A description of the physiological variables connected with an out-of-body study. Res. Parapsychol.: 36-37.

Jansen, K.L.R. (1989) Near-death experience and the NMDA receptor [Letter]. Br. Med. J., 298: 1708.

Jansen, K.L.R. (1997) The Ketamine model of the near-death experience: a central role for the N-Methyl-D-Aspartate receptor. J. Near Death Studies, 16(1): 5-27.

LaBerge, S. (1990) Lucid dreaming: psychophysiological studies of consciousness during REM sleep. In: Bootzen R.R., Kihlstrom J.F. and Schacter D.L. (Eds.), Sleep and Cognition. American Psychological Association, Washington, DC, pp. 109-126.

Letailleur, M., Morin, J. and Le Borgne, Y. (1958) Heautoscopie heterosexuelle et schizophrenie. Etude d'une observation. Ann. Méd.-Psych., 116: 451-461.

Leube, D.T., Knoblich, G., Erb, M., Grodd, W., Bartels, M. and Kircher, T.T. (2003) The neural correlates of perceiving one's own movements. Neuroimage, 20: 2084-2090.

Lhermitte, J. (1939) Les phénomènes héautoscopiques, les hallucinations spéculaires et autoscopiques. In: L'image de Notre Corps. L'Harmattan, Paris, pp. 170-227.

Lobel, E., Kleine, J.F., Blhan, D.L., Leroy-Willig, A. and Berthoz, A. (1998) Functional MRI of galvanic vestibular stimulation. J. Neurophysiol., 80: 2699-2709.

Lukianowicz, N. (1958) Autoscopic phenomena. Arch. Neurol. Psychiatry, 80: 199-220.

Lunn, V. (1970) Autoscopic phenomena. Acta Psychiatr. Scand., 46, 219: 118-125.

Maack, L.H. and Mullen, P.E. (1983) The Doppelgänger, disintegration and death: a case report. Psychol. Med., 13(3): 651-654. 
Maguire, E.A., Burgess, N., Donnett, J.G., Frackowiak, R.S., Frith, C.D. and O'Keefe, J. (1998) Knowing where and getting there: a human navigation network. Science, 280: 921-924.

Maillard, L., Vignal, J.P., Anxionnat, R. and TaillandierVespignani, L. (2004) Semiologic value of ictal autoscopy. Epilepsia, 45: 391-394.

Mathew, R.J., Wilson, W.H., Coleman, R.E., Turkington, T.G. and DeGrado, T.R. (1997) Marijuana intoxication and brain activation in marijuana smokers. Life Sci., 60(23): 2075-2089.

Maquet, P. (2000) Functional neuroimaging of normal human sleep by positron emission tomography. J. Sleep Res., 9: 207-231.

Maquet, P., Degueldre, C., Delfiore, G., Aerts, J., Peters, J.M., Luxen, A. and Franck, G. (1997) Functional neuroanatomy of human slow wave sleep. J. Neurosci., 17: 2807-2812.

Maquet, P., Peters, J.M., Aerts, J., Delfiore, G., Degueldre, C., Luxen, A. and Franck, G. (1996) Functional neuroanatomy of human rapid eye movement sleep and dreaming. Nature, 383: $163-166$.

McConnel, W.B. (1965) The phantom double in pregnancy. Br. J. Psychiatry, 111: 67-68.

McCreery, C. (1993) Schizotypy and the out-of-body-experience. Unpublished doctoral dissertation, Oxford University, Oxford, England.

McCreery, C. and Claridge, G. (1995) Out-of-the body experiences and personality. J. Soc. Psychical Res., 60: 129-148.

McCreery, C. and Claridge, G. (1996a) A study of halluciantation in normal subjects: II. Electrophysiological data. Pers. Ind. Differences, 21: 749-758.

McCreery, C. and Claridge, G. (1996b) The factor structure of 'schizotypal' traits: a large replication study. Br. J. Clin. Psychol., 35: 103-115.

McCreery, C. and Claridge, G. (2002) Healthy schizotypy: the case of out-of-the-body experiences. Pers. Ind. Differences, 32: 141-154.

Meehl, P.E. (1962) Schizotaxia, schizotypy, schizophrenia. Am. Psychologist, 17: 827-838.

Menninger-Lerchenthal, E. (1935) Das Truggebilde der eigenen Gestalt (Heautoskopie, Doppelgänger). Karger, Berlin.

Metzinger, T. (2003) Being No One. MIT Press, Cambridge, MS.

Metzinger, T. (2005) The prescientific concept of a "soul": a neurophenomenological hypothesis about its origin. In: Peschl M.F. (Ed.), Die Rolle der Seele in der Kognitionswissenschaft und der Neurowissenschaft. Auf der Suche nach dem Substrat der Seele. Königshausen and Neumann, Germany, pp. 189-214.

Michel, C.M., Murray, M.M., Lantz, G., Gonzalez, S., Spinelli, L. and Grave De Peralta, R. (2004) EEG source imaging. Clin. Neurophysiol., 115: 2195-2222.

Mitchell, L.C. (1973) Out-of-the-body vision. Psychic: 44-47.

Moermann, N., Bonke, B. and Oosting, J. (1993) Awareness and recall during general Anesthesia. Anesthisiology, 79: 454-464.

Monroe, R.A. (1974) Journeys Out of the Body. Corgi, London.
Muldoon, S.J. and Carrington, H. (1929) The Projection of the Astral Body. Rider, London.

Muldoon, S.J. and Carrington, H. (1951) The Phenomena of Astral Projection. Rider, London.

Neisser, U. (1988) The five kinds of self-knowledge. Phil. Psychol., 1: 35-59.

Nielsen, T.A. (2003) A review of mentation in REM and NREM sleep: "Covert" REM sleep as a possible reconciliation of two opposing models. In: Pace-Schott E.F., Solms M., Blagrove M. and Harnad S. (Eds.), Sleep and Dreaming: Scientific Advances and Reconsiderations. Cambridge University Press, Cambridge, pp. 125-132.

Nofzinger, E.A., Mintun, M.A., Wiseman, M., Kupfer, D.J. and Moore, R.Y. (1997) Forebrain activation in REM sleep: an FDG PET study. Brain Res., 770: 192-201.

O'Leary, D.S., Block, R.I., Flaum, M., Schultz, S.K., Boles Ponto, L.L., Watkins, G.L., Hurtig, R.R., Andreasen, N.C. and Hichwa, R.D. (2000) Acute marijuana effects on rCBF and cognition: a PET study. NeuroReport, 17(27): 3835-3841.

O'Leary, D.S., Block, R.I., Koeppel, J., Flaum, M., Schultz, S.K., Andreasen, N.C., Boles Ponto, L.L., Watkins, G.L., Hurtig, R.R. and Hichwa, R.D. (2002) Effects of smoking marijuana on brain perfusion and cognition. Neuropsychopharmacology, 26(6): 802-816.

Osis, K. and Mitchell, J.L. (1977) Physiological correlates of reported out-of-body-experiences. J. Soc. Psychical Res., 49: $525-536$.

Ostermann, J.E., Hopper, J., Heran, W.J., Keane, T.M. and van der Kolk, B.A. (2001) Awareness under anaesthisia and the development of post traumatic stress disorder. Gen. Hosp. Psychiatry, 23: 193-204.

Ostrow, M. (1960) The metapsychology of autoscopic phenomena. Int. J. Psychoanal., 41: 619-625.

Palmer, J. (1978) ESP and out-of-body experiences: an experimental approach. In: Rogo D.S. (Ed.), Mind Beyond the Body. Penguin, Harmondsworth, England, pp. 193-217.

Palmer, J. (1979) A community mail survey of psychic experiences. J. Am. Soc. Psychical Res., 73: 221-251.

Perrin, F., Maquet, P., Peigneux, P., Ruby, P., Degueldre, C., Balteau, S., Del Fiore, G., Moonen, G., Luxen, A. and Laureys, S. (2005) Neural mechanisms involved in the detection of our first name: a combined ERPs and PET study. Neuropsychologia, 43: 12-19.

Poynton, J.C. (1975) Results of an out-of-body survey. In: Poynton J.C. (Ed.), Parapsychology in South Africa. South African Society for Psychical Research, Johannesburg, South Africa, pp. 109-123.

Ramachandran, V.S. and Hirstein, W. (1998) The perception of phantom limbs. Brain, 121: 1603-1630.

Ranta, S.O.V., Laurelia, R., Saario, J., Ali- Melkkilä, T. and Hynynen, M. (1998) Awareness with recall during general anesthesia: incidence and risk factors. Anesth. Analg., 86: 1084-1089.

Ravenhill, T.H. (1913) Some experiences of mountain sickness in the Andes. J. Trop. Med. Hyg., 16: 313-320.

Rechtschaffen, A. and Siegel, J. (2000) Sleep and dreaming. In: Kandel E.R.J., Schwartz J.J.H. and Jessel T.M. (Eds.), 
Principles of Neural Science (4th ed.). McGraw-Hill, New York, pp. 937-948.

Reynolds, M. and Brewin, C.R. (1999) Intrusive memory in depression and posttraumatic stress disorder. Behav. Res. Therapy, 37: 201-215.

Ring, K.R. (1980) Life at Death. A Scientific Investigation of the Near-Death Experience. Coward, McCann \& Geoghegan, New York.

Ringelstein, E.B. and Zunker, P. (1998) Low-flow infarction. In: Ginsberg M. and Bogousslavsky J. (Eds.) Cerebrovascular Disease: Pathophysiology, Diagnosis and Management, Vol. 2. Blackwell Science INC, Cambridge, pp. 1075-1089.

Rogo, D.S. (1982) Psychological models of the out of body experience. A review and critical evaluation. J. Parapsychol., 46: $29-45$.

Rogo, D.S. (1986) Leaving the Body. A Complete Guide to Astral Projection. Simon and Schuster, NY.

Röhricht, F. and Priebe, S. (1997) Disturbances of body experience in schizophrenic patients. Fortschr. Neurol. Psychiatr., 65(7): 323-336.

Ruby, P. and Decety, J. (2001) Effect of subjective perspective taking during simulation of action: a PET investigation of agency. Nat. Neurosci., 4: 546-550.

Ruby, P. and Decety, J. (2003) What you believe versus what you think they believe: a neuroimaging study of conceptual perspective-taking. Eur. J. Neurosci., 17(11): 2475-2480.

Ruby, P. and Decety, J. (2004) How do you feel versus how do you think she would feel? A neuroimaging study of perspective taking with social emotions. J. Cogn. Neurosci., 16(6): 988-999.

Salama, A.E.A.A. (1981) The autoscopic phenomenon: case report and review of literature. Can. J. Psychiatry, 26: 476.

Sandin, R.H. (2003) Awareness 1960-2002, explicit recall of events during general anesthesia. Adv. Exp. Med. Biol., 523: 135-147.

Sandin, R.H., Enlund, G., Samuelsson, P. and Lennmarken, C. (2000) Awareness during anesthesia: a prospective case study. Lancet, 355: 707-711.

Schmitt, B. (1948) L'heautoscopie. Cahiers de Psychiatrie, 2: 21-26.

Schwartz, S. and Maquet, P. (2002) Sleep imaging and the neuropsychological assessment of dreams. Trends Cog. Sci., 6(1): 23-30.

Sheils, D. (1978) A cross-cultural study of beliefs in out-of-thebody experiences, waking and sleeping. J. Soc. Psychol. Res., 49: 697-741.

Shermer, M. (1998) A mind out of body. Skeptic, 6(3): 72-79.

Siegel, R.K. (1977) Hallucinations. Sci. Am., 237: 132-140.
Smith, B.H. (1960) Vestibular disturbances in epilepsy. Neurology, 10: 465-469.

Sours, J.A. (1965) The "Break-Off" phenomenon. A precipitant of anxiety in jet aviators. Arch. Gen. Psychiatr., 13: 447-456.

Spitellie, P.H., Holmes, M.A. and Domino, K.B. (2002) Awareness during anesthesia. Anesthisiol. Clin. N. Am., 20: 555-570.

Tart, C.T. (1967) A second psychophysiological study of the out-of-the-body experiences in a selected subject. Int. J. Parapsychol., 9(3): 251-258.

Tart, C.T. (1968) A psychophysiological study of the out-ofthe-body experiences in a selected subject. J. Am. Soc. Psychical Res., 62: 3-27.

Tart, C.T. (1970) Marijuana intoxication: common experiences. Nature, 226: 701-704.

Tart, C.T. (1971) On Being Stoned. A Psychological Study of Marijuana Intoxication. Science and Behavior Books, Palo Alto.

Tart, C.T. (1974) Out-of-body experiences. In: White J. (Ed.), Psychic Exploration: A Challenge for Science. Putnam, New York, pp. 349-373.

Tart, C.T. (1975) States of Consciousness. Dutton, New York.

Tormes, F.R. and Guedry, F.E. (1975) Disorientation phenomena in naval helicopter pilots. Aviat. Space Environ. Med., 46: 387-393.

Twemlow, S.W. (1977) Epilogue: personality file. In: Monroe R.A. (Ed.), Journeys Out of the Body. Anchor, New York, pp. 275-280.

Twemlow, S.W., Gabbard, G.O. \& Jones, F.C. (1980) The outof-body experience: I. Phenomenology. Paper presented at the annual meeting of the American Psychiatric Association, San Francisco.

Twemlow, S.W., Gabbard, G.O. and Jones, F.C. (1982) The out-of-body experience: a phenomenological typology based on questionnaire responses. Am. J. Psychiatry, 139: 450-455.

Volkow, N.D., Gillespie, H., Mullani, N., Tancredi, L., Grant, C., Valentine, A. and Hollister, L. (1996) Brain glucose metabolism in chronic marijuana users at baseline and during marijuana intoxication. Psychiatry Res.: Neuroimaging, 67: 29-38.

Wolfradt, U. and Watzke, S. (1999) Deliberate out-of-bodyexperiences, depersonalization, schizotypal traits and thinking styles. J. Amer. Soc. Psy. Res., 93: 249-257.

Zacks, J.M., Ollinger, J.M., Sheridan, M.A. and Tversky, B. (2002) A parametric study of mental spatial transformations of bodies. Neuroimage, 16: 857-872.

Zutt, J. (1953) "Aussersichsein" und "auf sich selbst Zurückblicken" als Ausnahmezustand. Zur Psychopathologie des Raumerlebens. Nervenarzt, 24: 24-31. 